\title{
Erratum to: Differential transformation method for Newtonian and Non-Newtonian fluids flow analysis: comparison with HPM and numerical solution
}

\author{
M. Hatami ${ }^{1}$ J. Hatami ${ }^{2}$ M. Jafaryar ${ }^{3}$ G. Domairry ${ }^{4}$
}

Published online: 1 June 2016

(C) The Brazilian Society of Mechanical Sciences and Engineering 2016

Erratum to: J Braz. Soc. Mech. Sci. Eng. (2016)

38:589-599

DOI 10.1007/s40430-014-0275-3

The original version of this article unfortunately contained a mistake.

The affiliation of the second author was incorrect. The correct information is given below.

J. Hatami, Semnan University of Medical Sciences, Semnan, Iran

The online version of the original article can be found under doi:10.1007/s40430-014-0275-3.

M. Hatami

m.hatami2010@gmail.com

$\bowtie$ J. Hatami

javad.hatamy@gmail.com

1 Mechanical Engineering Department, Esfarayen University

of Technology, Esfarayen, North Khorasan, Iran

2 Semnan University of Medical Sciences, Semnan, Iran

3 Mechanical Engineering Department, Mazandaran Institute of Technology, Babol, Iran

4 Mechanical Engineering Faculty, Babol University of Technology, Babol, Iran 